\title{
Factors affecting quality management in business: Evidence in Vietnam manufacturing and tech- nology enterprises
}

\author{
Vu Ngoc Xuan ${ }^{a^{*}}$ and Nguyen Thang Trunga
}

${ }^{a}$ Center for Analysis Forecasting and Sustainable Development, National Economics University, Vietnam

\begin{tabular}{l}
\hline C H R O N I C L E \\
\hline Article history: \\
Received: October 16, 2019 \\
Received in revised format: \\
January 302020 \\
Accepted: February 2, 2020 \\
Available online: \\
February 3, 2020 \\
\hline Keywords: \\
Quality management (QM) \\
Quality management system \\
(QMS) \\
Enterprises (Es)
\end{tabular}

\section{A B S T R A C T}

\begin{abstract}
This paper aimed to evaluate the factors affecting quality management (QM) through the quality management system according to ISO 9001 standards of Vietnam businesses. The authors surveyed on 200 manufacturing and technology enterprises that apply ISO 9001 quality management in Hanoi and Da Nang and HCMC. Factors affecting the effectiveness of quality management under ISO 9001 include five elements: (1) Management commitment; (2) Staff involvement; (3) Cooperation of customers and suppliers; (4) Consultants; and (5) Quality management document system. Research results show that the above factors had positive impacts on the effectiveness of the quality management system (QMS). The study has given a number of solutions for businesses that have been and will apply QMS in accordance with ISO 9001 with appropriate adjustments to promote the efficiency of the system.
\end{abstract}

(C) 2020 by the authors; licensee Growing Science, Canada

\section{Introduction}

ISO 9001 is a set of standards for QMS issued by the International Organization for Standardization (ISO) in 1987, and introduced in Vietnam in the 1990s. According to Vietnam Productivity Center, the number of enterprises received ISO 9001 certificate in Vietnam has increased from 13 certificates in 1997 to 184 enterprises in 2000, 612 enterprises in 2002, 2,461 enterprises in 2005, 4,282 enterprises in 2007 and over 6000 enterprises in 2010. From 2016 to 2019, the average annual number of ISO 9001 certificates reached about 5,000-6,000 annually. The increasing number of enterprises applying ISO 9001 shows that QMS following ISO 9001 has more or less brought benefits to businesses. However, the effectiveness of QMS really promotes and brings long-term benefits for businesses depending on whether the businesses continue to maintain and improve QMS after certification. Studies in Vietnam related to QMS in accordance with ISO 9001 in recent years mainly consider the impact of implementing ISO 9001 on businesses (Xuan et al., 2020), the impact of applying ISO 9001 on business performance (Xuan et al., 2020), factors affecting the satisfaction of industrial enterprises with QMS according to ISO 9001 (Xuan et al., 2020). There is currently no study to determine the factors affecting the effectiveness of QMS according to the ISO 9001 standard of businesses in Vietnam. Zouita et al. (2019) studied the impact of the local small and medium enterprises (SMEs) on foreign direct investment (FDI) and the mediating effect of IFRS adoption in developing economies refer the ISO 9001 in the FDI firms in EU and Algeria. Different studies by Thürer et al. (2014, 2015, 2016, 2019) also confirm the positive effects of the quality management in firms in European countries in general and Morocco in particular. Portioli-Staudacher et al. (2020) performed an investigation on the use of labor flexibility for output management in workload management. The objective of the present study is to explore the factors and determine the impacts of these factors on the effectiveness of QMS according to ISO 9001 standards of businesses in Ho Chi Minh City. 


\section{Theoretical foundations and research models}

\subsection{ISO 9001}

ISO 9001 is a set of QMS standards issued by ISO organization to set standards for QMS. It can be widely applied in businesses operating in the fields of production, business, services and nonprofits (Van den Heuvel et al., 2005; Piskar \& Dolinsek, 2006). By the end of 2011, the current set of ISO 9001 standards includes the following (İlkay \& Aslan, 2012):

- $\quad$ ISO 9001: 2005 (ISO 9001: 2007) describes the basis of QMS and defines terms for QMS.

- ISO 9001: 2008 (ISO 9001: 2008) specifies requirements for QMS when an organization needs to demonstrate its ability to deliver products that meet customer requirements and regulatory requirements, respectively, to improve customer satisfaction.

- ISO 9004: 2009 provides quality management guidelines to achieve sustainable success for all organizations in a complex operating environment with the stringent and constantly changing requirements of the market.

- ISO 19011: 2011 provides guidance on auditing management systems, including QMS, environmental management systems, food safety management systems and other management systems.

The standards of the ISO 9001 series have been accepted as Vietnam standards issued with the symbol ISO 9001.

The requirements of the current ISO 9001 series are shown in ISO 9001: 2008 (equivalent with ISO 9001: 2008). This standard is called ISO 9001: 2008 - QMS - Requirements. When applying the standard, the organization should develop, document, implement, maintain QMS and continually improve the effectiveness of the system in accordance with the requirements of this standard.

\subsection{Quality management principles}

The content of the ISO 9001 standard is built on the basis of quality management principles (ISO 9001: 2007):

\section{Customer-oriented}

Every organization depends on its customers, so it needs to understand the current and future needs of its customers, it needs to meet customer requirements and try to exceed their expectations.

Leadership: Leadership establishes unity between the purpose and direction of the organization. Management needs to create and maintain an internal environment so that it can fully engage people to achieve organizational goals.

Participation of everyone: People at all levels are important elements of an organization. Mobilizing them to full participation will help to use their competencies for the benefit of the organization.

Process-driven approach: The desired outcome will be effectively achieved when the resources and related activities are managed as a process.

Systematic approach to management: Identifying, understanding and managing interrelated processes as a system will bring the effectiveness and efficiency of the organization to achieve its goals.

Continuous improvement: Continuous improvement of performance results must be an ongoing goal of the organization.

Decision based on facts: All effective decisions are based on data and information analysis.

Mutually beneficial cooperation with suppliers: Organizations and suppliers who are interdependent and mutually beneficial will enhance both sides' capacity to create value.

\subsection{The effectiveness of QMS in accordance with ISO 9001}

According to ISO 9001: 2007, QMS is a management system to direct and manage an organization for quality. In it, a management system is a collection of interrelated or interacting elements to set policies and goals and to achieve those goals. Quality orientation and management include quality policy setting and quality objectives, quality planning, quality management, quality assurance and quality improvement (Pambreni et al., 2019).

According to ISO 9001: 2007, the effectiveness of QMS is the relationship between the results achieved and the resources used. As such, the effectiveness of QMS is the relationship between the results achieved by system operation and the necessary resources used to operate the system (Imran et al., 2018). 
The results achieved by QMS are expressed through the degree to which quality objectives are set at all levels and each functional part of the organization in the short or long term. The necessary resources used to operate QMS include: human resources, infrastructure, working environment, finance, etc.

The construction and operation of QMS in accordance with ISO 9001 aim to satisfy the customer requirements with specific, well-defined and quality-oriented goals next year higher than the previous year will motivate the departments as well as each member of the organization to work hard to achieve objectives, thus promoting the work efficiency of each department and the organization.

\section{The factors that affect the effectiveness of QMS according to ISO 9001:}

Based on the quality management principles and required content of ISO 9001, the effectiveness of an organization's QMS depends on the fundamental elements:

\section{- $\quad$ The commitment of senior leaders}

Through leadership and concrete actions, senior management of the organization creates an environment in which every member is mobilized to participate so that the organization's QMS can be run effectively and effectively. The senior management of an organization can use the principles of quality management as the basis for fulfilling its leadership role in QMS (Saffar \& Obeidat, 2020).

In order to build a successful and effective QMS, the organization's senior leadership must be at the forefront of all quality efforts. Management must believe in the philosophy of ISO 9001 quality management, and must commit to the organization's long-term quality goals; Since then, direct and participate in the development of QMS as well as take appropriate measures to mobilize the active and creative participation of all people in the organization to achieve the set goals.

\section{- Participation of members in the organization}

A characteristic of QMS in accordance with ISO 9001 must be built in the form of documents and operated on the basis of that document. However, if the quality management document system in the organization is fully developed but does not guarantee the active participation of people, QMS will not actually operate; activities and processes are conducted subjectively by implementers, so it is difficult to manage and easily arise non-compliance. This makes the effectiveness of QMS in the organization will decrease (Afthanorhan et al., 2019).

Employee engagement demonstrates their role and responsibility in adhering to the company's quality management documents, as well as suggestions for improvement of these documents to make them more appropriate to ensure that operations are performed to produce the required results (Jenab et al., 2018).

\section{- Supplier support}

The operations of an organization always need to use resources such as materials, machinery, energy, etc. The provision of these elements ensures the requirements of the organization in terms of quality, quantity and time. The supply will facilitate business operations in a stable manner, so that the organization can ensure that the product meets the highest level of customer requirements (Ul-Hameed et al., 2019).

The cooperation between customers and suppliers is essential and plays an important role for businesses to conduct stable activities and processes to create products that meet the requirements of customers and stakeholders. Providing specific information about the product requirements as well as feedback on the quality of the product / service received will help the business understand the customer requirements and have a basis to proceed improved quality to increase customer satisfaction. In addition, receiving inputs (raw materials, energy, etc.) to ensure stability in quality, quantity and clear origin will help businesses ensure stability in the process, production process as well as easy traceability of the product when there is a problem to fix and improve promptly.

\section{- The support of the consultant}

Self-development and implementation of an organization's QMS can be difficult, as unbiased when assessing the situation and comparing with the requirements of the standard, it takes significant amount of time to find the direction and progress for implementing the steps of building and applying the system. Therefore, the support of qualified and experienced consultants will help the organization's QMS shortening time, saving resources and quickly putting the system into operation and exploit the benefits brought about by this system. 
The quality management documentation system makes it possible to notify intentions and consistency in action (ISO 9001: 2007). The use of a document system helps the organization achieve compliance with customer requirements and improve quality; provides appropriate training to members of the organization; management the repetition of processes and traceability of products easily; provides objective evidence of system operation, as a basis for evaluating the effectiveness and appropriateness of your organization's QMS.

Each organization should determine the level of necessary documentation and media used. This depends on factors such as size and type of organization, product complexity, customer requirements, staff capacity and the level needed to demonstrate the fulfillment of the requirements. The system of quality management documents is clearly and understandably understood, reflecting the actual operation of the organization, which will help employees easily management the quality of work and product quality, thereby ensuring ensure effective operation of QMS and contribute to improving the efficiency of the system.

\subsection{Scale}

The scale of research concepts in the model is built from a theoretical basis and qualitative preliminary research, using a 5step Likert format where 1 represents totally disagree until 5 denotes totally agree. The scale of the commitment component of management is measured by four observed variables with the content referring to: (1) senior leaders have confidence in benefits; (2) understanding of nature; (3) aware of its important role; and (4) consistently pursuing the goals in QMS according to ISO 9001. The medium management role scale is measured by four observed variables with the following contents: (1) monitoring; (2) close coordination in process formulation; (3) exchanging information in process implementation; and (4) receive process improvement suggestions. The scale of employee participation is measured by 5 observed variables with the content referring to: (1) performance of the process; (2) realize the importance of following the process; (3) understand the processes relevant to your work; (4) participate in process improvement proposals; and (5) voluntarily follow the process. The internal information system scale is measured by 4 observed variables with the content: (1) internal information system; (2) timely information of documents that have changed; (3) information is updated regularly; and (4) members easily obtain the information needed to carry out the work. The scale of the composition of customer and supplier cooperation is measured by 5 observation variables that focus on: (1) customer feedback on the quality of the company's products / services; (2) ensure a stable supply of quality; (3) quantity; (4) sufficient documents of origin; and (5) provide products / services required by the company. The scale of consultants is measured by 4 observed variables with the content referring to: (1) experience in implementing QMS; (2) understanding the field of operations of the company; (3) insight into QMS; and (4) have good communication skills. The quality management documentation system scale is measured by four observed variables that mention: (1) conformity; (2) clear and easy to understand; (3) easy to apply; and (4) ease of management of the QM documentation system. Finally, the QMS efficiency scale is measured by 6 observed variables in order to: (1) help the company improve customer satisfaction; (2) rational use of resources; (3) reduce waste; (4) time saving work done; (5) achieve quality objectives; and (6) the effectiveness of QMS in accordance with ISO 9001. All scales in the model are omnidirectional scales.

The model of researching the factors that affect the effectiveness of QMS according to ISO 9001 in businesses is shown as follows:

QMS efficiency $=\mathrm{f}($ Employees, Leadership Commitment, Middle Management, Systems documents, Consultant, Customers and Suppliers, Information Systems)

\section{Research Methodology and Results research}

\subsection{Sample}

The authors used a direct interview technique with detailed questionnaires with staff, managers and employees working in enterprises that apply QMS according to ISO 9001. The survey period was from June 2018 to September 2019. The sample was selected according to a convenient method with a sample size of 300 . There were 300 questionnaires issued, 300 votes were collected, in which 290 satisfactory votes were input for analysis and treatment using SPSS software. The statistical results show that: Regarding the working position: the director has 19 people (accounting for 6.55\%); Deputy head of office has 55 people (accounting for 18.96\%); There were 216 employees directly involved in QMS operation (accounting for $74.48 \%$ ). Regarding seniority of work: only 7 people work for less than 1 year (accounting for $2.41 \%$ ); there are 71 people working from 1 to 3 years (accounting for 24.48\%); There were 212 people working over 3 years (accounting for $73.1 \%$ ).

\subsection{Analysis of research results}

Preliminary test by factor analysis (EFA), the results show that there are 6 groups of factors extracted at eigenvalue was 1.064 , with extraction variance is $73.47 \%(>50 \%)$. The scale after EFA test has 25 variables. The middle management scale was eliminated (all 4 observed variables). After the KHVCC 1 variable of the customer and supplier scale was removed, this scale was given a new name as "Supplier" (NCC), since the remaining variables only related to suppliers. Cronbach's Alpha 
reliability test for 6 factors, showing that the scales meet the reliability requirements, the Cronbach Alpha coefficient ranges from 0.857 to 0.910 (Table 1). Testing the Efficacy of QMS by EFA analysis extracted one element at eigenvalue is 3.920 , with extraction variance of $65.34 \%$ (greater than $50 \%$ ) satisfactory. Continuing to test the reliability of the scale showed satisfaction with the reliability of 0.893 .

Table 1

Summary of scale test results

\begin{tabular}{|c|c|c|c|c|c|}
\hline Concept & Factor & $\begin{array}{c}\text { Number of Variables } \\
\text { Observed }\end{array}$ & Reliability & Variance & Assessment \\
\hline \multirow{6}{*}{$\begin{array}{l}\text { Factors affecting the } \\
\text { effectiveness of QMS }\end{array}$} & Staff & 5 & 0.888 & \multirow{6}{*}{$73.4 \%$} & \multirow{7}{*}{ Satisfactory } \\
\hline & Leadership commitment & 4 & 0.873 & & \\
\hline & System document & 4 & 0.910 & & \\
\hline & Consultants & 4 & 0.895 & & \\
\hline & Suppliers & 4 & 0.857 & & \\
\hline & Information systems & 4 & 0.889 & & \\
\hline QMS efficiency & & 6 & 0.895 & $65.348 \%$ & \\
\hline
\end{tabular}

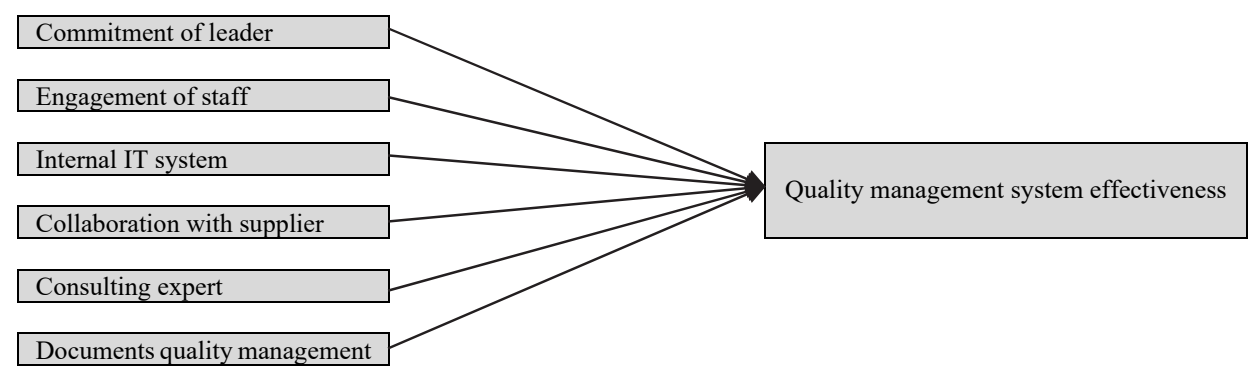

Fig. 1. The proposed method

Adjustment of research model: After preliminary analysis, the research model was adjusted to 6 components instead of 7 components as originally proposed (Fig. 1): or present in the regression equation. Selecting a step-by-step independent variable is a combination of phasing and elimination procedures. After each step, variables in the equation are again considered for exclusion. There are 5 models formed after analysis. Research selected model 5 because that was the best model. The final result of the step-by-step method was partly extracted and presented in Table 3. Table 3 shows that there are 5 factors that affect the efficiency of QMS (Sig value. $<0.05$ so they are significant). statistics), they are: "Employees", "Leadership Commitments", "Documentation Systems", "Consultants" and "Suppliers". The "Information system" element is excluded.

The regression equation has the form:

Effective QMS $=0.246$ Document system +0.223 Commitment of leadership +0.222 Employee +0.157 Consultant +0.153 Supplier

Check the assumptions of the regression model:

- There is a linear relationship between the dependent variable (QMS efficiency) and the independent variables (6 variables), constant variance: The results show the relationship between the standardized predicted value and the standard residual value. Thus, these two assumptions are not violated.

- Assumption of standard normal distribution of residuals: The result of some graphical statistics shows that this is a standard approximation distribution.

The regression analysis is used to determine the factors and the degree of impact of these factors on QMS efficiency. With the assumption that "Effective QMS" is linearly related to the above 6 factors, we have the following regression equation:

Effective QMS $=a+b_{1} \times$ Staff $+b_{2} \times$ Commitment to leadership $+b_{3} \times$ Document system $+b_{4} \times$ Consultant $+b_{5} \times$ Customers and suppliers $+b_{6} \times$ Information system $+e_{i}$

bi: Coefficient of regression equation ei: Residual 
Since this model was newly built (not a repeating model), so the research team used a step-wise regression method to discover the independent variables correlated with the dependent variable 0 and standard deviation $\approx 1$ ). So, this assumption is not violated.

- Assumption of no correlation between independent variables: The VIF value of the independent variables is less than 2 (Table 2), so there is no multicollinearity.

- Assumption of independence of error: Durbin-Watson coefficient is 1,936 , so this assumption is not violated.

Test results of assumptions show that the regression model is suitable.

Table 2

The summary of the results

\begin{tabular}{|c|c|c|c|c|c|c|c|}
\hline & Model & Coefficients & Standard Deviation & $\begin{array}{l}\text { Coefficients } \\
\text { Standardized }\end{array}$ & T- Value & Tolerance & VIF \\
\hline \multirow[t]{2}{*}{1} & Constant & 1.626 & 0.196 & & 8.305 & & \\
\hline & The documentation & 0.576 & 0.051 & 0.623 & 11.306 & 1.000 & 1.000 \\
\hline \multirow[t]{6}{*}{2} & Constant & 0.402 & 0.222 & & 1.813 & & \\
\hline & The documentation & 0.228 & 0.059 & 0.246 & 3.882 & 0.548 & 1.823 \\
\hline & Commitments Leadership & 0.202 & 0.058 & 0.223 & 3.509 & 0.547 & 1.828 \\
\hline & Employees & 0.198 & 0.049 & 0.222 & 4.012 & 0.723 & 1.382 \\
\hline & Consultant & 0.136 & 0.055 & 0.157 & 2.481 & 0.553 & 1.808 \\
\hline & Suppliers & 0.132 & 0.054 & 0.135 & 2.441 & 0.720 & 1.389 \\
\hline
\end{tabular}

\section{Discussion and results}

Weak elements of the QM document system have the strongest impact on the effectiveness of QMS $($ Beta $=0.246)$. This is consistent with the theory and qualitative research results. An outstanding feature of QMS in accordance with ISO 9001 is that an enterprise's QMS must be established as a document. The company's QMS is operated, maintained and improved on the basis of this document system. The commitment of senior management has the second strongest impact on the effectiveness of QMS (Beta = 0.223). This is also consistent with the theory and qualitative research results. The prerequisite for effective QMS of the business is the commitment and commitment of senior management of the business. If senior leaders do not commit at a high level, it means that the leaders would not care much about QMS, would not have strict management, would not direct drastically, so it is difficult for the company's QMS is valid and not as effective as expected. Factor Employee participation has the 3rd strongest impact on QM performance $($ Beta $=0.222)$. Participation is an indispensable principle to operate and improve QMS. Qualitative research shows that even though the quality management document system is built to ensure the best performance for employees to perform the work, if the document system is not compliant during the operation and the system is running, QMS will not be effective. Since the employees' failure to comply with the procedures and regulations in the QM document system means that employees work according to subjective intentions, so it is easy to generate errors and repeated errors (due to not being completely overcome), wasting resources in the enterprise and failing to achieve the set quality objectives. The support factor of the consultant has a weaker effect than the above three factors on the effectiveness of QMS (Beta = 0.157). In practice, the application of ISO 9001 standard often makes it difficult for enterprises to understand the content of the requirements of the standard and contact the application of the standard to suit the operating characteristics of enterprises. Without the support from qualified and experienced consultants, businesses often spend significant amount of time in understanding the requirements of ISO 9001 standards as well as building a system of QM documents. The factor of supplier cooperation has the lowest but also significant impact on the effectiveness of QMS $($ Beta $=0.135)$. Practices show that the receipt of raw materials, energy, machinery and equipment in accordance with the requirements of the business in terms of quality, quantity and schedule of supply will create favorable conditions for businesses in ensure production and business progress, achieve quality objectives and contribute to ensuring the supply of products / services that meet the requirements of customers. Internal information system element has no impact on QMS effectiveness. Quantitative research shows that this factor is measured by four observed variables. However, regression analysis has shown that this factor had no effect on the efficiency of QMS $(p=0.1102>0.05$, which was excluded from the regression model). Thus, it can be said that with the survey data set it is not possible to conclude clearly whether the internal information element has an impact on the effectiveness of QMS. This is an issue that needs further review and verification in subsequent studies.

\section{Recommendations for businesses}

From the research results, in order to promote the effectiveness of QMS in accordance with ISO 9001 in businesses, managers should pay attention to the following factors: quality management document system, commitment of senior management, high and staff involvement.

- To ensure that QMS of an enterprise operates effectively, it requires that the document system must be built in accordance with the operational practices of the enterprise; the content of documents must be clear, easy to understand and easy to apply; each document must have management information to ensure its availability, easy access when needed, and correct use of the document. 
- The commitment of senior leaders of the business is a prerequisite to build success and promote the effectiveness of QMS. Whether or not the improvement of the enterprise's QM system is implemented, whether it is really effective or not, depends very much on the leadership's determination to pursue the application of ISO 9001 standard, senior management's knowledge of its important role in promoting the application of ISO 9001.

- Staff plays an important role in the operation, improvement and improvement of QMS. Therefore, businesses need to train them with a proper awareness of QMS in accordance with ISO 9001, mobilize their participation through appropriate incentives policies both physically and mentally; evaluate employees based on the quality and efficiency of their work, associating employee benefits with the interests of the business; define their responsibilities and authority in their work to encourage their dynamism, creativity and activism as well as to ensure adequate provision of resources necessary for them to perform their jobs well, achieve Quality objectives have been set.

In addition to focusing on these three factors, businesses should also pay attention to the capacity and experience of consultants in the field of business operations when selecting consultants to support the QMS development process of the business. This will help the process of building the QM document system of the business shorten time and quickly put the company's QMS into operation and promote the effectiveness of the company's QMS. In selecting suppliers, businesses need to develop a system of supplier evaluation criteria (stability of quality, quantity, time of supply, etc. at the request of the enterprise) and conduct assessment. competency pricing of suppliers periodically in order to have good cooperation of suppliers in ensuring always supplying the inputs of the process of creating products of the enterprise in accordance with the requirements of the business, from that enables businesses have enough capacity to best meet the increasing requirements of customers.

\section{Acknowledgement}

The authors would like to thank the anonymous referees for constructive comments on earlier version of this paper.

\section{References}

Afthanorhan, A., Awang, Z., Rashid, N., Foziah, H., \& Ghazali, P. (2019). Assessing the effects of service quality on customer satisfaction. Management Science Letters, 9(1), 13-24.

İlkay, M. S., \& Aslan, E. (2012). The effect of the ISO 9001 quality management system on the performance of SMEs. International Journal of Quality \& Reliability Management, 29(7), 753-778.

Imran, M., Aziz, A., Hamid, S., Shabbir, M., Salman, R., \& Jian, Z. (2018). The mediating role of total quality management between entrepreneurial orientation and SMEs export performance. Management Science Letters, 8(6), 519-532.

Jenab, K., Wu, C., \& Moslehpour, S. (2018). Design for six sigma: A review. Management Science Letters, 8(1), 1-18.

Louail, B. (2019). Determinants of foreign direct investment in Arab countries during 1970-2016. International Journal of Advanced and Applied Sciences, 6(3) 2019, Pages: 102-110.

Louail, B. (2015, June). Economic openness and its impact in the growth of the Algerian economy during the period 19702012. In 3rd INTERNATIONAL SCIENTIFIC FORUM, ISF 2015 22-25 April, Amman, Jordan (p. 59).

Saffar, N., \& Obeidat, A. (2020). The effect of total quality management practices on employee performance: The moderating role of knowledge sharing. Management Science Letters, 10(1), 77-90.

Thürer, M., Stevenson, M., Qu, T., \& Godinho Filho, M. (2014). The design of simple subcontracting rules for make-to-order shops: An assessment by simulation. European Journal of Operational Research, 239(3), 854-864.

Thürer, M., Stevenson, M., \& Qu, T. (2015). Simple subcontracting rules for make-to-order shops with limited subcontractor capacity: an assessment by simulation. Production Planning \& Control, 26(13), 1145-1161.

Thürer, M., Stevenson, M., \& Land, M. J. (2016). On the integration of input and output control: Workload Control order release. International Journal of Production Economics, 174, 43-53.

Thürer, M., Stevenson, M., Land, M. J., \& Fredendall, L. D. (2019). On the combined effect of due date setting, order release, and output control: an assessment by simulation. International Journal of Production Research, 57(6), 1741-1755.

Ul-Hameed, W., Shabbir, M., Imran, M., Raza, A., \& Salman, R. (2019). Remedies of low performance among Pakistani elogistic companies: The role of firm's IT capability and information communication technology (ICT). Uncertain Supply Chain Management, 7(2), 369-380.

Pambreni, Y., Khatibi, A., Azam, S., \& Tham, J. (2019). The influence of total quality management toward organization performance. Management Science Letters, 9(9), 1397-1406.

Piskar, F., \& Dolinsek, S. (2006). Implementation of the ISO 9001: from QMS to business model. Industrial Management \& Data Systems, 106(9), 1333-1343.

Portioli-Staudacher, A., Costa, F., \& Thürer, M. (2020). The use of labour flexibility for output control in workload controlled flow shops: A simulation analysis. International Journal of Industrial Engineering Computations, 11(3). DOI: 10.5267/j.ijiec.2019.11.004.

Van den Heuvel, J., Koning, L., Bogers, A. J., Berg, M., \& van Dijen, M. E. (2005). An ISO 9001 quality management system in a hospital. International Journal of Health Care Quality Assurance, 18(5), 361-369.

Xuan, V., Thu, N., \& Anh, N. (2020). Factors affecting the business performance of enterprises: Evidence at Vietnam small and medium-sized enterprises. Management Science Letters, 10(4), 865-870. 
Zouita, M.S., Louail, B., \& Mameche, Y. (2019). The impact of the local SMEs sector on FDI and the mediating effect of IFRS adoption in developing economies: The case of Algeria. International Journal of Advanced and Applied Sciences, $6(11), 120-129$.

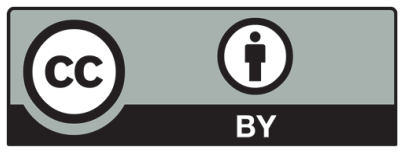

(C) 2020 by the authors; licensee Growing Science, Canada. This is an open access article distributed under the terms and conditions of the Creative Commons Attribution (CC-BY) license (http://creativecommons.org/licenses/by/4.0/). 